\title{
URBANICITY: THE NEED FOR NEW AVENUES TO EXPLORE THE LINK BETWEEN URBAN LIVING AND PSYCHOSIS
}

\author{
Lilith Abrahamyan Empson ${ }^{1}$, Philipp S. Baumann ${ }^{1,2}$, Ola Söderström ${ }^{3}$, Zoe \\ Codeluppi $^{3}$, Dag Söderström ${ }^{4}$, Philippe Conus ${ }^{1}$
}

1. Treatment and early Intervention in Psychosis Program, Service of General Psychiatry, Department of Psychiatry, Lausanne University Hospital CHUV Switzerland

2. Center for Psychiatric Neurosciences, Department of Psychiatry, Lausanne University Hospital CHUV, Switzerland

3. Institute of Geography, University of Neuchâtel, Espace Louis-Agassiz, 2000 Neuchâtel, Switzerland

4. Psychiatrist, Avenue de la Gare 16, 1800 Vevey, Switzerland

\author{
Corresponding author \\ Lilith Abrahamyan Empson \\ Département de Psychiatrie \\ Service de Psychiatrie Générale \\ Hôpital Psychiatrique de Cery \\ 1008 Prilly \\ Switzerland \\ Email: lilith.abrahamyan-empson@chuv.ch
}

Keywords: Psychosis, schizophrenia, risk factors, environmental risk, urbanicity.

Total word count: 5105

Abstract word count: 239

This is the author manuscript accepted for publication and has undergone full peer review but has not been through the copyediting, typesetting, pagination and proofreading process, which may lead to differences between this version and the Version of Record. Please cite this article as doi: 10.1111/eip.12861

This article is protected by copyright. All rights reserved. 


\section{ABSTRACT}

Background: A growing body of evidence suggests that urban living contributes to the development of psychosis. However, the mechanisms underlying this phenomenon remain unclear. This paper aims to explore the best available knowledge on the matter, identify research gaps and outline future prospects for research strategies.

Method: A comprehensive literature survey on the main computerised medical research databases, with a time limit up to August 2017 on the issue of urbanicity and psychosis has been conducted.

Results: The impact of urbanicity may result from a wide range of factors (from urban material features to stressful impact of social life) leading to "urban stress". The latter may link urban upbringing to the development of psychosis through overlapping neuro- and socio-developmental pathways, possibly unified by dopaminergic hyperactivity in mesocorticolimbic system. However, "urban stress" is poorly defined and research based on patients' experience of the urban environment is scarce.

Conclusions: Despite accumulated data, the majority of studies conducted so far failed to explain how specific factors of urban environment combine in patients' daily life to create protective or disruptive milieus. This undermines the translation of a vast epidemiological knowledge into effective therapeutic and urbanistic developments. New studies on urbanicity should therefore be more interdisciplinary, 
bridging knowledge from different disciplines (psychiatry, epidemiology, human geography, urbanism etc.) in order to enrich research methods, ensure the development of effective treatment and preventive strategies as well as create urban environments that will contribute to mental wellbeing.

\section{INTRODUCTION}

A city is a human settlement forming a complex system providing individuals with important resources but also exposing them to potential adversities. A growing body of evidence converge to suggest that "urbanicity", the impact of living in urban areas at a given time (Vlahov \& Galea, 2002), is a risk factor for the later development of psychosis with a critical time window for exposure during childhood (C. Bø. Pedersen \& Mortensen, 2001). The mechanisms underlying this link remain however unclear, consequently limiting the possibilities to translate this observation into useful preventive treatment strategies. The fact that more than $50 \%$ of the World population lives in cities (United Nations Population Fund, n.d.), a proportion likely to increase in the future, makes the resolution of this question an urgent matter.

The aims of this paper are threefold. First, we provide a survey of the scientific literature studying the link between urbanicity and psychosis in order to identify the concepts used so far to clarify this issue and the hypotheses that have emerged from them. Second, we identify gaps and domains where information is either lacking or ill defined. Third, we propose new ways to tackle this important issue, focusing on the

This article is protected by copyright. All rights reserved. 
need both to include patients' point of view and to expand the approach in the frame of interdisciplinary collaborations.

\section{METHODS}

We conducted a comprehensive literature survey on the main computerised medical research databases (EMBASE, MEDLINE Ovid SP, PSYCINFO, PubMed) in order to identify the body of literature published up to August 2017 on the issue of urbanicity and psychosis (for details, refer to appendix). We first included articles in English and French treating epidemiological data, etiological and neurobiological underpinnings of psychosis, if they contained urbanicity as an environmental risk factor, and then completed the database with hand-searched references. The aim of this survey paper is to summarize and organise the existing literature in such a way that we can identify limitations and define new directions for further research. Therefore, some studies including only healthy individuals or focusing on aspects of the urban environment that may be potentially risk increasing were also included, considering they may shed light on hypothetical psychopathological mechanisms. Studies based on specific populations such as elderly, conscripts, patients suffering from a physical condition or a mental handicap, were however excluded.

\section{RESULTS}

\subsection{EPIDEMIOLOGICAL DATA SUGGESTING A LINK BETWEEN URBANICITY} AND PSYCHOSIS

This article is protected by copyright. All rights reserved. 
The suggestion that the urban environment may constitute a risk factor for the later emergence of schizophrenia emerged in the 1930's. In his seminal work on psychosis in migrants, Ødegård, (1932) advanced the "selective migration theory" to explain the excess of psychiatric hospital admissions in migrants compared to the native population, a hypothesis according to which migrants were more prone to develop psychosis. A few years later, Faris, R. E. \& Dunham, H. W., (1939) observed in their study of Chicago a centre-periphery pattern with the highest concentrations of cases of schizophrenia in the city centre, a pattern that they did not find for manicdepressive psychosis. They however excluded the so-called 'social drift' hypothesis (a downward shift in social class linked in our case to the emergence of schizophrenia and psychosis), which periodically resurfaces in the literature (Goldberg \& Morrison, 1963; Hudson, 2012). They considered that people suffering from schizophrenia were not in poor central area because their illness drove them there, but because of their lack of social integration and hence their isolation, which is characteristic of those areas.

However, the search for a "biological" and mainly genetic cause to schizophrenia overshadowed the interest for the urbanicity and psychosis link during almost five decades. But the awareness of the complexities of genetic and neurobiological mechanisms progressively toned down ambitions for the discovery of a "simple" biological explanation, and the emergence of new concepts suggesting an interaction between genes and environment created a context where the impact of urban upbringing found its place again in the list of possible risk factors for schizophrenia. A new wave of epidemiological publications based on various designs and locations has, since then, clearly confirmed the higher prevalence of schizophrenia in urban

This article is protected by copyright. All rights reserved. 
centres (J. Allardyce et al., 2001; Judith Allardyce et al., 2005; Kirkbride et al., 2006, 2017; Kirkbride, Jones, Ullrich, \& Coid, 2014; Marcelis, Navarro-Mateu, Murray, Selten, \& Van Os, 1998; Mortensen et al., 1999; C. Bø. Pedersen \& Mortensen, 2001; Sørensen et al., 2014; Sundquist, Frank, \& Sundquist, 2004; Szöke et al., 2014; Van Os, 2004; Zammit et al., 2010). In addition, any doubts about potential research artefacts have been ruled out by various review papers and meta-analyses which converge in confirming the presence of a correlation between urban upbringing and risk to develop schizophrenia (McGrath et al., 2004; Cantor-Graae and Selten 2005; Krabbendam and van Os, 2005; Allardyce and Boydell 2006; March et al., 2008; Van Os et al. 2008; Kelly et al., 2010; Vassos et al., 2012; Heinz et al., 2013 ; Vilain et al., 2013; Penkalla et Kohler 2014 ; Gruebner et al., 2017).

Existing data (Marcelis et al., 1998; Pedersen and Mortensen 2001; Krabbendam and van Os, 2005; Kirkbride et al., 2006 and 2014; Laursen et al., 2007) suggests that this correlation isn't specific to schizophrenia alone and that it can also be observed with other forms of non-affective psychoses. The link between urban upbringing and increased risk to develop mood and/or anxiety disorders is less documented but is suggested by some authors (Peen, Schoevers, Beekman, \& Dekker, 2010).

In addition, Pedersen and Mortensen (1999 and 2001) have reported a linear dose response relationship between the risk to develop schizophrenia and the number of years spent in a highly urban environment before age 15. Moreover, Marcelis et al. (1998) and Carsten Bøcker Pedersen \& Mortensen (2001), observed a mitigation of the risk of psychosis in children born in cities who later moved to rural areas, and an increased risk in subjects who grew up in rural environment and moved to cities 
during adolescence, adding support to the hypothesis of a direct impact of urbanicity. Finally, some data suggest the magnitude of this link is not negligible. Recent research shows that the "population attributable risk" (the proportion of cases that would not occur in a population if the risk factor was eliminated) for urbanicity, its proxy factors and any other risk factor in interaction with them is equal to $30 \%$ (Krabbendam \& van Os, 2005; Spauwen, Krabbendam, Lieb, Wittchen, \& van Os, 2004).

Taken together, these findings (effect size, consistency, specificity, temporality and biological gradient) fulfil at least 5 of Hill's 9 criteria of causation (Hill, 1965), and therefore confirm that limiting the explanation of increased prevalence of psychosis in cities to social drift or selective migration mechanisms is insufficient (Carsten Bøcker Pedersen, 2015; van der Ven et al., 2015). However, now that the correlation between exposure to urban environment during childhood and later development of psychosis seems well established, it has become increasingly critical to go to the next step and understand which specific features of urban living may explain this phenomenon, in the hope to develop preventive strategies.

Although the time limit of our survey is set for August 2017, it is important to note that a recent paper (DeVylder et al., 2018) doesn't confirm higher odds for psychosis in urban areas in low and middle-income countries. Similarly Colodro-Conde et al., 2018 suggest that individuals with increased genetic risk tend to live in urban/dense areas, an observation that nuances previous findings.

\subsection{DISENTANGLING THE "URBAN ENVIRONMENT" AND ITS INFLUENCE ON} PSYCHOSES

This article is protected by copyright. All rights reserved. 
Schizophrenia is a polygenic disorder with a nonlinear and highly variable course and presentation, depending on the timing, type, duration and severity of the exposure to risk factors (Maric \& Svrakic, 2012). The precise mechanism through which the interaction between genetic liability and environmental factors occurs remains however unclear. By analogy with cancer, the explanatory model of a "two hit" scenario has been proposed, where a genetic defect ("first hit" e.g. placental / foetal genes down-regulation etc.) would not result in illness unless combined with another genetic or environmental factor ("second hit"). Indeed, numerous elements, acting through various mechanisms, correlate with a higher risk to develop psychosis or schizophrenia.

While "urbanicity" belongs to the list of risk factors, it is a generic term, which probably covers a number of known as well as unknown and interconnected environmental and social risk factors. Explanations for the occurrence of this link fall into two main categories. The first line of thoughts suggests that living in a city leads to a higher rate of exposure to some of the risk factors identified so far (see the table for risk factors that are more relevant in an urban environment) and hence to higher probability to develop psychosis. The second suggests rather that some specific aspects of the urban environment itself, such as its physical complexity or the intensity of social interactions, may play a central role in the phenomenon. This second line has recently gained increasing attention in the frame of an emerging trend for experimental in-situ or virtual studies (Bromley, Mikesell, Mates, Smith, \& Brekke, 2012; Broome et al., 2013; Ellett, Freeman, \& Garety, 2008; Freeman,

This article is protected by copyright. All rights reserved. 
Emsley, et al., 2015; Freeman, Waller, et al., 2015; Söderström et al., 2016; Wright, Peters, Ettinger, Kuipers, \& Kumari, 2014) where the impact of the environment on patients can be measured.

In the following sections of this paper, we will (A) firstly describe factors that may link psychosis and urbanicity due to their higher prevalence in city contexts, secondly explore the concept of "urban stress" and finally describe various neurobiological mechanisms that have been proposed so far.

\subsubsection{Factors that may explain the link between psychosis and urbanicity due to their higher prevalence in city contexts}

Some authors have suggested that both exposure to infectious agents during pregnancy (Brown, 2011; Brown et al., 2004; Susser, Schaefer, Brown, Begg, \& Wyatt, 2000; Torrey, Bartko, Lun, \& Yolken, 2007; Yolken, Dickerson, \& Torrey, 2009) and obstetric complications (Eaton, Mortensen, \& Frydenberg, 2000) may occur at a higher rate in urban environment. Similarly, some authors suggested that deficit in vitamin $D$ is more frequent in cities than in rural environment (McGrath, 1999; McGrath, Burne, Féron, Mackay-Sim, \& Eyles, 2010). However, a study showed that difference in the rate of non-affective psychoses between urban and non-urban samples remained significant after controlling for the potential effect of these factors, suggesting that urban living during childhood in itself drives the risk for the development of the disorder (Harrison et al., 2003).

In a similar fashion, it has been suggested that cannabis abuse, a well identified risk factor for the development of psychosis (Degenhardt et al., 2009; Henquet, Murray, 
Linszen, \& van Os, 2005; Moore et al., 2007), is more prevalent in urban samples. However, here again, significant differences in prevalence of psychosis between urban and non-urban populations are maintained after controlling for this variable, suggesting that other mechanisms are involved (Kuepper, van Os, Lieb, Wittchen, \& Henquet, 2011).

\subsubsection{The concept of "Urban stress"}

Despite the frequent use of this term both in scientific papers and more generally in the media, the precise nature of "urban stress" remains poorly defined. Although it is most of the time used as an umbrella term, various scientific publications provide interesting information about its possible components, which may be relevant to the urbanicity-psychosis nexus.

3.2.2.a. The built environment may affect mental health in various ways, not only by increasing the exposure to infectious agents, light, traffic, noise or pollution, but also, by becoming "psychotoxic" by itself. Indeed, urban design (tall and impressive buildings, narrow streets with no escape ways, billboards and flashing light containing instructions and meanings) may shape and alter individual behaviour and social exchanges. This could be linked, as proposed by Golembievski, to the fact that " $\ldots$ there is nowhere else where design is more ubiquitous than in the city, where literally every piece of rubbish carries meaning and potentially triggers action" (Golembiewski, 2013, 2017; Golembiewski, 2016). It is interesting to note, that recent imaging and EEG studies indicate distinct patterns of prefrontal activity when healthy 
subjects are exposed either to natural or urban environment, and that they report reduction of anxiety and tension when exposed to visual stimulation by nature (Chen, He, \& Yu, 2016; Igarashi, Song, Ikei, \& Miyazaki, 2015; Song et al., 2014). An obvious difference between city and rural areas is indeed the availability of green spaces. While the absence of noise, pollution and social stress may mediate its beneficial impact on psychological wellbeing, the restorative properties of the experience of nature may also be an important factor that deserves specific studies in schizophrenia (Tost, Champagne, \& Meyer-Lindenberg, 2015).

3.2.2.b. Auditory stimuli, ranging from noise of different nature and intensity to human speech (Gottschalk, Haer, \& Bates, 1972; Landon J, Shepherd D, McGarryy M, Theadom A, \& Miller R, 2016; Wright et al., 2014) is a salient component of an urban milieu. Some authors have reported higher sensibility to urban noise among patients suffering from schizophrenia (Tregellas et al., 2007; Tregellas, Ellis, Shatti, Du, \& Rojas, 2009). Furthermore, a recent study (El-Kaim et al., 2015) using realistic immersive environmental auditory scenes, established that schizophrenia patients, shown to have a higher sensitivity to nonstationary sounds (i.e with high rate of impacted acoustic features), had greater difficulties in combining stimuli into coherent representation than subjects from a control group, especially when it comes to negative or frightening emotional valence of the stimulus. These elements suggest a possible role for acoustic stimulations in the emergence or the persistence of psychotic symptoms.

This article is protected by copyright. All rights reserved. 
3.2.2.c. Environmental pollution is a major public health concern, and many authors suspect it could be involved in the link between urbanicity and psychosis. Pollutants potentially involved include heavy metals (lead and cadmium), constituents of air pollution and organic solvents (Attademo, Bernardini, Garinella, \& Compton, 2017; Brown, 2011; Kelly et al., 2010). In addition, given the impact of air pollution on the developing brain (Calderón-Garcidueñas, Torres-Jardón, Kulesza, Park, \& Angiulli, 2014; Dadvand et al., 2015), more research is clearly warranted to study its possible role in schizophrenia.

3.2.2.d. Urban milieu can also generate a stress of social nature. Indeed, various social interactions in a city can trigger a series of psychological situations (human aggression, bullying, exclusion or simply feeling inferior to others) that fall under the larger concept of "social defeat". Various authors have suggested that social defeat may play a significant role in the emergence of various psychiatric disorders (Björkqvist, 2001), among which schizophrenia (Selten \& Cantor-Graae, 2005).

3.2.2.e. Besides the general urban-rural gradient mentioned above, recent research has also established variations of the incidence of psychosis depending on neighbourhood characteristics. Neighbourhood studies have brought to light notions such as social capital and social fragmentation and disorganisation (Kelly et al., 2010; Kirkbride et al., 2014; O’Donoghue et al., 2016; W. Veling, Susser, Selten, \& Hoek, 2015), studying through these dimensions the potential impact of societal organization, community structure and degrees of interconnection with others, on the risk to develop schizophrenia and other psychoses. It is now accepted that the 
accumulation of traits that define an individual as different from others is a potential risk factor for psychosis (Abed \& Abbas, 2011; Tost \& Meyer-Lindenberg, 2012; Zammit et al., 2010). In addition, cumulative evidence demonstrates an inverse correlation between the risk to develop psychotic symptoms and the size of one's own ethnic group density (Boydell et al., 2001; Wim Veling et al., 2008) and ethnic identity (Anglin, Lui, Espinosa, Tikhonov, \& Ellman, 2016; Wim Veling, Hoek, Wiersma, \& Mackenbach, 2010). In line with this hypothesis, recent meta-analyses regularly confirm greater risk of psychosis among first and second-generation migrants across different ethnic groups and in different host countries (Cantor-Graae \& Selten, 2005; Kelly et al., 2010; Kirkbride et al., 2012; John McGrath et al., 2004; C. Morgan, Charalambides, Hutchinson, \& Murray, 2010). As mentioned above, accumulated data do not however support the selective migration theory according to which vulnerable and ill subjects are more likely to migrate (Kirkbride et al., 2012; Carsten Bøcker Pedersen, 2015; van der Ven et al., 2015). Along similar lines, other determinants of minority status have recently attracted interest and Gevonden et al. have suggested that the higher prevalence of psychotic symptoms among LGBT population may be linked to the experience of "minority stress" (Gevonden et al., 2014).

3.2.2.f. Some authors have suggested that early life traumatic experiences and violence in city dwellers may mediate the impact of urbanicity on the risk to develop psychosis (Frissen et al., 2015; Newbury et al., 2016). Considering that positive symptoms in general (Schreier et al., 2009) and paranoia in particular (Bentall, Wickham, Shevlin, \& Varese, 2012; Janssen et al., 2003) often follow experiences of 
trauma and victimization, the higher rate of violent acts in urban settings may indeed play a role.

\subsection{UNDERLYING MECHANISMS}

Although promising, regarding a better understanding of the link between urbanicity and psychosis, all the elements mentioned above are correlational and do not provide information concerning the mechanism that may concretely underlie this link. In the following section, we will attempt to bridge this gap based on available data.

While the best-established and most important risk factor for schizophrenia remains genetic liability, which possibly involves hundreds of genes(Mill et al., 2008), a consensus has emerged over the last decade around the possibility of an interaction between genes and environment (van Winkel, Stefanis, \& Myin-Germeys, 2008). Hence, when exploring the possible mechanisms underlying the link between urbanicity and psychosis, it is important to remember that human beings are in constant interaction with an environment that shapes the brain.

Acting during pre and postnatal periods, environmental risk factors of biological, physical or social nature, operate both at an individual level (for example family history of psychosis or migration, season of birth, obstetric complications, exposure to infections, toxins or pets, diet, household crowding, etc.) and at a group level (for example social capital, social fragmentation and deprivation). Their impact may operate through various mechanisms: epigenetic mis-regulation of normal genes (COMT, BDNF among others), silencing of protective genes (such as COMT Met/Met) increasing both the risk of schizophrenia and its symptom severity among 
cannabis users as reported by Caspi et al., 2005; Egan et al., 2001 or pathological continuation instead of age-related down-regulation of gene activity.

In addition, the ongoing influence of environmental risk factors during the life course may aggravate the initial impact through "stress sensitization". This additional mechanism may link chronic exposure to environmental stressors with psychotic symptoms through use-dependant functional augmentation of pathways that may progressively become "hardwired" (Weidenauer et al., 2017). This enhanced reactivity induced by environmental adversities involving multiple gene interactions may lead to the emergence as well as to the recurrence of psychotic symptoms.

Within the general framework through which gene-environment interaction occurs, there have been various attempts to explore the pathways involved in this process. Two partly overlapping concepts may explain the link between exposure to stressors and the later development of psychosis (Howes \& Murray, 2014) .

The neurodevelopmental pathway suggests that early life impairments of neurodevelopment may predispose persons to be more vulnerable to the impact of adverse social environments, and therefore increase the risk linked to prolonged exposure to negative life events (Demjaha, MacCabe, \& Murray, 2012). In other words, various environmental stressors may affect predisposed individuals in periods of biological or psychological vulnerability, especially during the phase where finetuning of cortical function is taking place (i.e. critical period).

The socio-developmental pathway, suggests that the experience of adverse social life events (such as prolonged periods of "social defeat" through chronic discrimination and segregation) may be linked to the progressive emergence of psychosis, either through the development of cognitive bias or through dopaminergic

This article is protected by copyright. All rights reserved. 
hyperactivity (Morgan et al., 2010; Morgan et al., 2002; Murray, Lappin, \& Di Forti, 2008). The dopaminergic hyperactivity in the mesocorticolimbic system in response to chronic stress exposure may actually be the common pathway unifying these two overlapping concepts. Indeed, social stress may link urban life and increased risk of psychosis through dopaminergic hyperactivity (Heinz \& Schlagenhauf, 2010; Howes et al., 2011; Kirkbride et al., 2007; Meyer-Lindenberg \& Tost, 2012; Mizrahi, 2016). Converging evidence from neuroimaging and animal studies suggest that an alteration of dopamine signalling may be the link between psychosocial stress and psychosis. While experimental studies in humans may be difficult to design for obvious ethical reasons, animal studies have shown that subcortical dopamine release may be affected in situations of social defeat (Covington and Miczek 2001; Morgan et al., 2002; Nader et al., 2006). This is in line with studies suggesting that, in humans, social defeat may be the underlying mechanism linking psychosocial adverse events to risk for psychosis (Selten, van der Ven, Rutten, \& Cantor-Graae, 2013). This seems to be supported by PET studies which have shown increased dopamine release proportional to the salivary cortisol response following psychosocial or metabolic stress in general population (Adler et al., 2000; Mizrahi et al., 2012; Pruessner, Champagne, Meaney, \& Dagher, 2004) as well as an exaggerated dopamine response in psychosis patients when exposed to stress, suggesting a sensitized dopaminergic system.

Furthermore, chronic stress has been shown to deregulate the hypothalamicpituitary-adrenal axis and to alter the maturation process of the brain (Steen et al., 2011). A set of recent functional magnetic resonance imaging studies have shown distinct impacts on social evaluative stress process (provision of negative comments 
on the performance of subjects) in humans with urban upbringing compared to subjects currently living in a city (Lederbogen et al., 2011). While urban upbringing appears to affect the perigenual anterior cingulate cortex (a key region for regulation of amygdala activity, negative affect and stress), current city living is associated with increased amygdala activity. In a sample of 110 healthy subjects, (Haddad et al., 2015) reported a strong inverse correlation between early-life urbanicity and grey matter volume in the right dorsolateral prefrontal cortex (DLPFC) and (in men only) of perigenual anterior cingular cortex $(\mathrm{pACC})$. A replication of these results has been recently published (Akdeniz et al., 2017). Volume reductions in the DLPFC has been linked to exposure to psychosocial stress, including stressful experiences in early life, and both anatomical and functional alterations of this region have been identified in schizophrenic patients and high-risk populations. In addition, data from Lederbogen et al. (2011) showed an elevated neural activity under social stress in the perigenual anterior cingulate cortex (pACC) in healthy adults who had lived in urban environment during their childhood. They concluded that these observations suggest a neural mechanism whereby early-life exposure to urban environment could impact brain architecture and increase the risk to develop schizophrenia, a finding later supported by Besteher, Gaser, Spalthoff, \& Nenadić, 2017. Nevertheless, there is no consensus on this question yet (see Frissen et al., 2017 for negative results).

Taken together, these findings tend to show that urban upbringing has an impact on some brain regions, which have been specifically implicated in the pathophysiology of schizophrenia (Tost et al., 2015) in line with the dysconnectivity hypothesis (Deserno, Sterzer, Wustenberg, Heinz, \& Schlagenhauf, 2012; Friston \& Frith, 1995; Stephan, Friston, \& Frith, 2009). The reduction of the control by dorsolateral 
prefrontal cortex (DLPFC) may contribute to impaired recognition and automatic responding to environmental cues and contexts. Combined with elevated subcortical dopamine turnover and release in acute psychosis (Abi-Dargham et al., 2000; Kumakura et al.,2007 ; Howes et al., 2012) this could result in aberrant salience (Kapur, 2003) and misinterpretation of otherwise irrelevant stimuli (Gray 1998; Corlett, Honey, and Fletcher 2007) leading to delusional formation.

Consequently urban stress, at least in a subgroup of patients, could be predominantly linked to hypersalience by sensory inundation ( Nelson, Parnas, \& Sass, 2014; Nelson, Whitford, Lavoie, \& Sass, 2014; Postmes et al., 2014), with varying behavioural impact, which may occur not only in the active phase of psychosis, but also during prodromal stages of the psychotic disorder or among the population at high risk for psychosis. Excessive sensory solicitation, be it acoustic, visual or olfactory, may operate as an important factor. Besides the unpredictability and intensity of each stimulus, their cumulative impact may also be involved in the mechanism. The sensation of inundation by sensory information, in particular concerning auditory modalities (Light \& Braff, 2003; Mcghie \& Chapman, 1961), as well as higher sensibility to urban noise among patients suffering from schizophrenia (Tregellas et al., 2007, 2009) have already been reported. In addition, some authors have suggested that perceptual inundation is a core anomaly in schizophrenia (Nelson et al., 2014; Postmes et al., 2014).

All these mechanisms may converge to induce alterations of sensory gating, leading in turn to perceptual modulation, over-inclusion, distractibility and fatigue-stress modulation, and giving rise to psychotic symptoms, such as hallucinations or delusions. This sequence may be particularly relevant in the urban environment 
where "every part of it is deliberately designed to assert meanings and messages" (Golembiewski, 2017).

\section{DISCUSSION}

Based on our literature survey, we can draw the following conclusions. First, the link between urban upbringing and increased risk to develop psychosis is well established in high income countries, considering it was replicated in numerous studies and meta-analyses and is maintained after controlling for a wide range of potential confounding factors as described above. Second, this impact is dosedependent and depends on the number of years spent during childhood and adolescence in a city environment. Third, although many different explanatory models have been proposed, none of them is seems sufficient to explain this link. In particular, the suggestion that increased exposure to risk factors (such as infections and substance abuse for example) when living in a city environment would explain the impact of urbanicity is not sufficient in itself to explain this correlation.

Therefore, it seems likely that the impact of urbanicity results from numerous factors that operate at different scales and which constitute the so called "urban stress" (Abbott, 2012), a phenomenon that plays a central role in linking urban upbringing to the development of psychosis. This concept of "urban stress" is however neither clearly defined, nor well studied. We think a better understanding of its nature is a critical element for progression in this domain of research and suggest that exploring the personal experience of patients should play a central role in this endeavour. Urban stress is multifaceted since it may result from the conjunction of numerous 
elements, ranging from exposure to multiple visual or auditory stimuli, complex and unpredictable traffic and crowd movements or pollution, to more complicated phenomena such as complex social interactions. Material features of the city as well as the stressful impact of social life may interact with the same neurobiological mechanisms mentioned above which may constitute a final common pathway for their impact.

Given the complexity of these mechanisms, the need for interdisciplinary collaborations is gaining increasing support (Adli et al., 2017). We have argued elsewhere (Söderström et al., 2016) that a shift of scale and viewpoint is necessary in order to improve our grasp on the role of specific urban situations and milieus. Both a better understanding of how urban stress is experienced and a more finegrained analysis of its various components are pre-requisites to the comprehension of its link to the development of psychotic phenomena. A change in research methodology is necessary in order to shift from urbanicity, generally conceptualized as an aggregate of statistical descriptors at the area level, to the level of an urban space composed of varied places and situations experienced by persons in their everyday life.

Interdisciplinary research provides a frame where such a change can occur. In a recent paper, we have detailed the methodology of a project that explores early psychosis patients' experience of urban environment applying methods stemming from various domains, ranging from psychiatry and epidemiology to social geography and urbanism. The study uses various methods, including video recordings of urban walks, semi-directive interviews, focus groups and a patient survey (Söderström et al., 2016; Söderström et al., 2017). Visual methodologies (such as video recorded go 
alongs) provide means to grasp bodily, sensorial and spatial dimensions as well as emotional reactions in different life situations (Doughty, 2013; Pink, 2007), and geographers have used them in research while working with people with mental health problems (Parr, 2007). In psychiatry, they were used in studies exploring neurocognitive abilities of patients in their everyday environment (Bromley et al., 2012). To the best of our knowledge, there is no prior use of video-recorded goalongs in urbanicity /psychosis studies, although these recordings constitute very concrete starting points to discuss with patients for whom producing narratives about themselves is often challenging due to their symptoms (Lysaker \& Lysaker, 2010). Video-recorded walk along based elicitations may provide a visual support to a population known for lack of narrative self, allowing the combination of a thorough sequential analysis of the elements identified as relevant by the patients themselves. In addition, the fine-grained interactional analysis of such videos may reveal elements such as discontinuities, hesitations and hitches in speech and bodily conduct of the patient, which may often escape the clinical observation because of their short duration or a low intensity. Sociologists, anthropologists and geographers often use such methods to understand the relation between a person and its environment in a more naturalistic manner.

\section{CONCLUSION}

Studies on urbanicity have attracted increasing attention over the last decade, contributing to a finer and multifaceted understanding of why it may increase the risk to develop psychosis. However, the vast majority of studies conducted so far failed to 
explore patients' perspective and studies including experiential /immersive dimensions remain scarce (Duff, 2012). This contributes to the fact that a translation of research findings into daily practice has so far been impossible. In addition, despite its important impact on patient's daily life, a structured and thorough investigation of the way patients experience their urban environment is not part of clinical practice and it is rare for patients to discuss it spontaneously. We believe this may be an important domain to explore and that the development of research exploring what happens for patients when they are facing urban stressors may contribute to a better understanding of how exactly city characteristics ranging from its physical aspects to more complex societal underpinnings interact and affect their wellbeing.

New studies on urbanicity should therefore be interdisciplinary in order to enrich research strategies beyond the present focus on epidemiology. This topic of research is very important, considering the growing proportion of the world population living in cities. Indeed, a better understanding of the link between urbanicity and psychosis may not only help to develop adaptive coping strategies; it may also contribute to shaping future cities in a better way in order to make them more adapted to human needs.

Acknowledgements: This survey has been conducted in the framework of a research funded by the FNS, through grant number 153320 to Ola Söderström and Philippe Conus. We would like to thank the case managers of 
the Treatment and early Intervention in Psychosis Program (TIPP) for their

support in this research as well as Joëlle Rosselet Amoussou for her help in

refining literature search strategies. P.S.B. is financially supported by the

Leenaards Foundation,

\title{
Appendix
}

\section{Embase}

('psychosis'/exp/dm_et,dm_ep OR (psychosis OR psychoses OR schizophrenia OR (psychotic NEXT/1 (symptom* OR disorder*)) OR (schizoaffective NEXT/1 disorder*) OR delusion* OR hallucination* OR paranoia OR paranoid):ab,ti) AND ('urban population'/exp OR 'urban area'/exp OR 'urbanization'/exp OR 'city'/exp OR 'population density'/de OR (((urban OR city OR cities) NEAR/3 (environment* OR stress OR living OR population* OR upbringing OR density)) OR urbanicity OR urbanisation OR urbanization OR 'population density' OR 'social density'):ab,ti)

\begin{abstract}
Medline OvidSP
(exp psychotic disorders/ep OR exp psychotic disorders/et OR exp schizophrenia/ep OR exp schizophrenia/et OR exp paranoid disorders/ep OR exp paranoid disorders/et OR exp delusions/ep OR exp delusions/et OR (psychosis OR psychoses OR schizophrenia OR (psychotic ADJ1 (symptom* OR disorder*)) OR (schizoaffective ADJ1 disorder*) OR delusion* OR hallucination* OR paranoia OR paranoid).ab,ti.) AND (exp urban population/ OR exp cities/ OR exp urbanization/ OR exp urban health/ OR exp population density/ OR (((urban OR city OR cities) ADJ3 (environment* OR stress OR living OR population* OR upbringing OR density)) OR urbanicity OR urbanisation OR urbanization OR "population density" OR "social density").ab,ti.)
\end{abstract}

\section{Psyclnfo}

(exp psychosis/ OR exp delusions/ OR (psychosis OR psychoses OR schizophrenia OR (psychotic ADJ1 (symptom* OR disorder*)) OR (schizoaffective ADJ1 disorder*) OR delusion* OR hallucination* OR paranoia OR paranoid).ab,ti.) AND (exp urban environments/ OR exp urbanization/ OR exp social densityl OR (((urban OR city OR cities) ADJ3 (environment* OR stress OR living OR population* OR upbringing OR density)) OR urbanicity OR urbanisation OR urbanization OR "population density" OR "social density").ab,ti.)

\section{Pubmed NOT Medline[sb] limited to references not indexed for Medline}

("'Psychotic Disorders/epidemiology"[Mesh] OR "Psychotic Disorders/etiology"[Mesh] OR "Schizophrenia/epidemiology"[Mesh] OR "Schizophrenia/etiology"[Mesh] OR "Paranoid Disorders/epidemiology"[Mesh] OR "Paranoid Disorders/etiology"[Mesh] OR "Delusions/epidemiology"[Mesh] OR "Delusions/etiology"[Mesh] OR psychosis[tiab] OR psychoses[tiab] OR schizophrenia[tiab] OR psychotic symptom*[tiab] OR psychotic disorder*[tiab] OR schizoaffective disorder*[tiab] OR delusion*[tiab] OR hallucination*[tiab] OR paranoia[tiab] OR paranoid[tiab]) AND ("Urban Population"[Mesh] OR "Cities"[Mesh] OR "Urbanization"[Mesh] OR "Urban Health"[Mesh] OR "Population Density"[Mesh] OR urban 
environment*[tiab] OR "urban stress"[tiab] OR "urban living"[tiab] OR urban population*[tiab] OR "urban upbringing" OR "urban density"[tiab] OR city environment*[tiab] OR "city stress"[tiab] OR "city living"[tiab] OR city population*[tiab] OR "city density"[tiab] OR cities environment*[tiab] OR "social density"[tiab])) NOT Medline[sb]

\section{References}

Abbott, A. (2012). Stress and the city: Urban decay. Nature News, 490(7419), 162. https://doi.org/10.1038/490162a

Abed, R. T., \& Abbas, M. J. (2011). A reformulation of the social brain theory for schizophrenia: the case for out-group intolerance. Perspectives in Biology and Medicine, 54(2), 132-151. https://doi.org/10.1353/pbm.2011.0020

Abi-Dargham, A., Rodenhiser, J., Printz, D., Zea-Ponce, Y., Gil, R., Kegeles, L. S., ... Laruelle, M. (2000). Increased baseline occupancy of D2 receptors by dopamine in schizophrenia. Proceedings of the National Academy of Sciences of the United States of America, 97(14), 81048109.

Adler, C. M., Elman, I., Weisenfeld, N., Kestler, L., Pickar, D., \& Breier, A. (2000). Effects of acute metabolic stress on striatal dopamine release in healthy volunteers. Neuropsychopharmacology, 22(5), 545-550.

Adli, M., Berger, M., Brakemeier, E.-L., Engel, L., Fingerhut, J., GomezCarrillo, A., ... Stollmann, J. (2017). Neurourbanism: towards a new discipline. The Lancet. Psychiatry, 4(3), 183-185. https://doi.org/10.1016/S2215-0366(16)30371-6

Akdeniz, C., Schäfer, A., Streit, F., Haller, L., Wüst, S., Kirsch, P., ... Meyer- 
Lindenberg, A. (2017). Sex-Dependent Association of Perigenual Anterior Cingulate Cortex Volume and Migration Background, an Environmental Risk Factor for Schizophrenia. Schizophrenia Bulletin, 43(4), 925-934. https://doi.org/10.1093/schbul/sbw138

Allardyce, J., \& Boydell, J. (2006). Review: the wider social environment and schizophrenia. Schizophrenia Bulletin, 32(4), 592-598. https://doi.org/10.1093/schbul/sbl008

Allardyce, J., Boydell, J., Os, J. V., Morrison, G., Castle, D. J., Murray, R. M., \& McCREADIE, R. G. (2001). Comparison of the incidence of schizophrenia in rural Dumfries and Galloway and urban Camberwell. The British Journal of Psychiatry, 179(4), 335-339. https://doi.org/10.1192/bjp.179.4.335

Allardyce, J., Gilmour, H., Atkinson, J., Rapson, T., Bishop, J., \& McCreadie, R. G. (2005). Social fragmentation, deprivation and urbanicity: relation to first-admission rates for psychoses. The British Journal of Psychiatry, 187(5), 401-406.

Anglin, D. M., Lui, F., Espinosa, A., Tikhonov, A., \& Ellman, L. (2016). Ethnic identity, racial discrimination and attenuated psychotic symptoms in an urban population of emerging adults. Early Intervention in Psychiatry. https://doi.org/10.1111/eip.12314

Attademo, L., Bernardini, F., Garinella, R., \& Compton, M. T. (2017).

Environmental pollution and risk of psychotic disorders: A review of the 
science to date. Schizophrenia Research, 181, 55-59.

https://doi.org/10.1016/j.schres.2016.10.003

Bentall, R. P., Wickham, S., Shevlin, M., \& Varese, F. (2012). Do Specific Early-Life Adversities Lead to Specific Symptoms of Psychosis? A Study from the 2007 The Adult Psychiatric Morbidity Survey. Schizophrenia Bulletin, 38(4), 734-740.

https://doi.org/10.1093/schbul/sbs049

Besteher, B., Gaser, C., Spalthoff, R., \& Nenadić, I. (2017). Associations between urban upbringing and cortical thickness and gyrification. Journal of Psychiatric Research, 95, 114-120. https://doi.org/10.1016/j.jpsychires.2017.08.012

Björkqvist, K. (2001). Social defeat as a stressor in humans. Physiology \& Behavior, 73(3), 435-442. https://doi.org/10.1016/S00319384(01)00490-5

Boydell, J., van Os, J., McKenzie, K., Allardyce, J., Goel, R., McCreadie, R. G., \& Murray, R. M. (2001). Incidence of schizophrenia in ethnic minorities in London: ecological study into interactions with environment. BMJ : British Medical Journal, 323(7325), 1336.

Bromley, E., Mikesell, L., Mates, A., Smith, M., \& Brekke, J. S. (2012). A video ethnography approach to assessing the ecological validity of neurocognitive and functional measures in severe mental illness: results from a feasibility study. Schizophrenia Bulletin, 38(5), 981-991. 
https://doi.org/10.1093/schbul/sbr002

Broome, M. R., Z\&\#xe1, Nyi, E., Hamborg, T., Selmanovic, E., Czanner, S., ... Singh, S. P. (2013). A High-Fidelity Virtual Environment for the Study of Paranoia [Research article]. Retrieved 6 August 2017, from https://www.hindawi.com/journals/schizort/2013/538185/

Brown, A. S. (2011). The environment and susceptibility to schizophrenia. Progress in Neurobiology, 93(1), 23-58. https://doi.org/10.1016/j.pneurobio.2010.09.003

Brown, A. S., Begg, M. D., Gravenstein, S., Schaefer, C. A., Wyatt, R. J., Bresnahan, M., ... Susser, E. S. (2004). Serologic evidence of prenatal influenza in the etiology of schizophrenia. Archives of General Psychiatry, 61(8), 774-780. https://doi.org/10.1001/archpsyc.61.8.774

Brown, A. S., Schaefer, C. A., Quesenberry, C. P., Liu, L., Babulas, V. P., \& Susser, E. S. (2005). Maternal exposure to toxoplasmosis and risk of schizophrenia in adult offspring. The American Journal of Psychiatry, 162(4), 767-773. https://doi.org/10.1176/appi.ajp.162.4.767

Calderón-Garcidueñas, L., Torres-Jardón, R., Kulesza, R. J., Park, S.-B., \& Angiulli, A. D'. (2014). Air pollution and detrimental effects on children's brain. The need for a multidisciplinary approach to the issue complexity and challenges. Frontiers in Human Neuroscience, 8. https://doi.org/10.3389/fnhum.2014.00613

Cantor-Graae, E., \& Selten, J.-P. (2005). Schizophrenia and migration: a 
meta-analysis and review. The American Journal of Psychiatry, 162(1), 12-24. https://doi.org/10.1176/appi.ajp.162.1.12

Caspi, A., Moffitt, T. E., Cannon, M., McClay, J., Murray, R., Harrington, H., ... Craig, I. W. (2005). Moderation of the Effect of Adolescent-Onset Cannabis Use on Adult Psychosis by a Functional Polymorphism in the Catechol-O-Methyltransferase Gene: Longitudinal Evidence of a Gene X Environment Interaction. Biological Psychiatry, 57(10), 1117-1127. https://doi.org/10.1016/j.biopsych.2005.01.026

Chen, Z., He, Y., \& Yu, Y. (2016). Enhanced functional connectivity properties of human brains during in-situ nature experience. PeerJ, 4, e2210. https://doi.org/10.7717/peerj.2210

Colodro-Conde, L., Couvy-Duchesne, B., Whitfield, J. B., Streit, F., Gordon, S., Kemper, K. E., ... Martin, N. G. (2018). Association Between Population Density and Genetic Risk for Schizophrenia. JAMA Psychiatry, 75(9), 901.

https://doi.org/10.1001/jamapsychiatry.2018.1581

Corlett, P. R., Honey, G. D., \& Fletcher, P. C. (2007). From prediction error to psychosis: ketamine as a pharmacological model of delusions. Journal of Psychopharmacology (Oxford, England), 21(3), 238-252. https://doi.org/10.1177/0269881107077716

Covington, H. E., \& Miczek, K. A. (2001). Repeated social-defeat stress, cocaine or morphine. Effects on behavioral sensitization and 
intravenous cocaine self-administration 'binges'. Psychopharmacology, 158(4), 388-398. https://doi.org/10.1007/s002130100858

Dadvand, P., Nieuwenhuijsen, M. J., Esnaola, M., Forns, J., Basagaña, X., Alvarez-Pedrerol, M., ... Sunyer, J. (2015). Green spaces and cognitive development in primary schoolchildren. Proceedings of the National Academy of Sciences, 112(26), 7937-7942.

https://doi.org/10.1073/pnas.1503402112

Degenhardt, L., Hall, W. D., Lynskey, M., McGrath, J., McLaren, J., Calabria, B., ... Vos, T. (2009). Should Burden of Disease Estimates Include Cannabis Use as a Risk Factor for Psychosis? PLoS Medicine, 6(9). https://doi.org/10.1371/journal.pmed.1000133

Demjaha, A., MacCabe, J. H., \& Murray, R. M. (2012). How genes and environmental factors determine the different neurodevelopmental trajectories of schizophrenia and bipolar disorder. Schizophrenia Bulletin, 38(2), 209-214. https://doi.org/10.1093/schbul/sbr100

Deserno, L., Sterzer, P., Wustenberg, T., Heinz, A., \& Schlagenhauf, F. (2012). Reduced Prefrontal-Parietal Effective Connectivity and Working Memory Deficits in Schizophrenia. Journal of Neuroscience, 32(1), 1220. https://doi.org/10.1523/JNEUROSCI.3405-11.2012

DeVylder, J. E., Kelleher, I., Lalane, M., Oh, H., Link, B. G., \& Koyanagi, A. (2018). Association of Urbanicity With Psychosis in Low- and MiddleIncome Countries. JAMA Psychiatry, 75(7), 678. 
https://doi.org/10.1001/jamapsychiatry.2018.0577

Doughty, K. (2013). Walking together: the embodied and mobile production of a therapeutic landscape. Health \& Place, 24, 140-146. https://doi.org/10.1016/j.healthplace.2013.08.009

Duff, C. (2012). Exploring the role of 'enabling places' in promoting recovery from mental illness: a qualitative test of a relational model. Health \& Place, 18(6), 1388-1395.

https://doi.org/10.1016/j.healthplace.2012.07.003

Eaton, W. W., Mortensen, P. B., \& Frydenberg, M. (2000). Obstetric factors, urbanization and psychosis. Schizophrenia Research, 43(2-3), 117123.

Egan, M. F., Goldberg, T. E., Kolachana, B. S., Callicott, J. H., Mazzanti, C. M., Straub, R. E., ... Weinberger, D. R. (2001). Effect of COMT Val108/158 Met genotype on frontal lobe function and risk for schizophrenia. Proceedings of the National Academy of Sciences of the United States of America, 98(12), 6917-6922. https://doi.org/10.1073/pnas.111134598

El-Kaim, A., Aramaki, M., Ystad, S., Kronland-Martinet, R., Cermolacce, M., Naudin, J., ... Micoulaud-Franchi, J.-A. (2015). On the correlation between perceptual inundation caused by realistic immersive environmental auditory scenes and the sensory gating inventory in schizophrenia. European Psychiatry: The Journal of the Association of 
European Psychiatrists, 30(5), 606-614.

https://doi.org/10.1016/j.eurpsy.2015.01.005

Ellett, L., Freeman, D., \& Garety, P. A. (2008). The psychological effect of an urban environment on individuals with persecutory delusions: the Camberwell walk study. Schizophrenia Research, 99(1-3), 77-84. https://doi.org/10.1016/j.schres.2007.10.027

Farías, I. (n.d.). 2016 - Urban Cosmopolitics: Agencements, Assemblies, Atmospheres. Retrieved from https://www.academia.edu/28974038/2016__Urban_Cosmopolitics_Agencements_Assemblies_Atmospheres

Faris, R. E., \& Dunham, H. W. (1939). Mental disorders in urban areas: An ecological study of schizophrenia and other psychoses. Chicago/London: The University of Chicago Press.

Freeman, D., Emsley, R., Dunn, G., Fowler, D., Bebbington, P., Kuipers, E., ... Garety, P. (2015). The Stress of the Street for Patients With Persecutory Delusions: A Test of the Symptomatic and Psychological Effects of Going Outside Into a Busy Urban Area. Schizophrenia Bulletin, 41(4), 971-979. https://doi.org/10.1093/schbul/sbu173

Freeman, D., Waller, H., Harpur-Lewis, R. A., Moore, R., Garety, P., Bebbington, P., ... Jolley, S. (2015). Urbanicity, persecutory delusions, and clinical intervention: the development of a brief CBT module for helping patients with persecutory delusions enter social urban 
environments. Behavioural and Cognitive Psychotherapy, 43(1), 4251. https://doi.org/10.1017/S1352465813000660

Frissen, A., Lieverse, R., Drukker, M., van Winkel, R., Delespaul, P., \& GROUP Investigators. (2015). Childhood trauma and childhood urbanicity in relation to psychotic disorder. Social Psychiatry and Psychiatric Epidemiology, 50(10), 1481-1488.

https://doi.org/10.1007/s00127-015-1049-7

Frissen, A., van Os, J., Lieverse, R., Habets, P., Gronenschild, E., \& Marcelis, M. (2017). No Evidence of Association between Childhood Urban Environment and Cortical Thinning in Psychotic Disorder. PLoS ONE, 12(1). https://doi.org/10.1371/journal.pone.0166651

Friston, K. J., \& Frith, C. D. (1995). Schizophrenia: a disconnection syndrome? Clinical Neuroscience (New York, N.Y.), 3(2), 89-97.

Gevonden, M. J., Selten, J. P., Myin-Germeys, I., de Graaf, R., Have, M. ten, van Dorsselaer, S., ... Veling, W. (2014). Sexual minority status and psychotic symptoms: findings from the Netherlands Mental Health Survey and Incidence Studies (NEMESIS). Psychological Medicine, 44(2), 421-433. https://doi.org/10.1017/S0033291713000718

Goldberg, E. M., \& Morrison, S. L. (1963). Schizophrenia and Social Class. The British Journal of Psychiatry, 109(463), 785-802. https://doi.org/10.1192/bjp.109.463.785

Golembiewski, J. (2013). Lost in space: The place of the architectural milieu in 
the aetiology and treatment of schizophrenia. Facilities, 31(9/10), 427448. https://doi.org/10.1108/02632771311324981

Golembiewski, J. (2017). Architecture, the urban environment and severe psychosis. Part l: Aetiology. (Vol. Journal of Urban Design and Mental Health).

Golembiewski, J. A. (2016). The Designed Environment and How it Affects Brain Morphology and Mental Health. HERD, 9(2), 161-171. https://doi.org/10.1177/1937586715609562

Gottschalk, L. A., Haer, J. L., \& Bates, D. E. (1972). Effect of Sensory Overload on Psychological State: Changes in Social AlienationPersonal Disorganization and Cognitive-Intellectual Impairment. Archives of General Psychiatry, 27(4), 451-457. https://doi.org/10.1001/archpsyc.1972.01750280019004

Gray, J. A. (1998). Integrating schizophrenia. Schizophrenia Bulletin, 24(2), 249-266.

Gruebner, O., Rapp, M. A., Adli, M., Kluge, U., Galea, S., \& Heinz, A. (2017). Cities and Mental Health. Deutsches Arzteblatt International, 114(8), 121-127. https://doi.org/10.3238/arztebl.2017.0121

Haddad, L., Schäfer, A., Streit, F., Lederbogen, F., Grimm, O., Wüst, S., ... Meyer-Lindenberg, A. (2015). Brain Structure Correlates of Urban Upbringing, an Environmental Risk Factor for Schizophrenia. Schizophrenia Bulletin, 41(1), 115-122. 
https://doi.org/10.1093/schbul/sbu072

Harrison, G., Fouskakis, D., Rasmussen, F., Tynelius, P., Sipos, A., \&

Gunnell, D. (2003). Association between psychotic disorder and urban place of birth is not mediated by obstetric complications or childhood socio-economic position: a cohort study. Psychological Medicine, 33(4), 723-731. https://doi.org/10.1017/S0033291703007591

Heinz, A., Deserno, L., \& Reininghaus, U. (2013). Urbanicity, social adversity and psychosis. World Psychiatry, 12(3), 187-197.

https://doi.org/10.1002/wps.20056

Heinz, A., \& Schlagenhauf, F. (2010). Dopaminergic Dysfunction in Schizophrenia: Salience Attribution Revisited. Schizophrenia Bulletin, 36(3), 472-485. https://doi.org/10.1093/schbul/sbq031

Henquet, C., Murray, R., Linszen, D., \& van Os, J. (2005). The environment and schizophrenia: the role of cannabis use. Schizophrenia Bulletin, 31(3), 608-612. https://doi.org/10.1093/schbul/sbi027

Hill, A. B. (1965). The Environment and Disease: Association or Causation? Proceedings of the Royal Society of Medicine, 58(5), 295-300.

Howes, O. D., Bose, S. K., Turkheimer, F., Valli, I., Egerton, A., Valmaggia, L. R., ... Mcguire, P. (2011). Dopamine Synthesis Capacity Before Onset of Psychosis: A Prospective [18F]-DOPA PET Imaging Study. The American Journal of Psychiatry, 168(12), 1311-1317.

Howes, O. D., Kambeitz, J., Kim, E., Stahl, D., Slifstein, M., Abi-Dargham, A., 
$\&$ Kapur, S. (2012). The nature of dopamine dysfunction in schizophrenia and what this means for treatment. Archives of General Psychiatry, 69(8), 776-786.

https://doi.org/10.1001/archgenpsychiatry.2012.169

Howes, O. D., \& Murray, R. M. (2014). Schizophrenia: an integrated sociodevelopmental-cognitive model. Lancet (London, England), 383(9929), 1677-1687. https://doi.org/10.1016/S0140-6736(13)62036$x$

Hudson, C. (2012). Patterns of Residential Mobility of People with Schizophrenia: Multi-level Tests of Downward Geographic Drift. The Journal of Sociology \& Social Welfare, 39(3). Retrieved from http://scholarworks.wmich.edu/jssw/vol39/iss3/9

Igarashi, M., Song, C., Ikei, H., \& Miyazaki, Y. (2015). Effect of Stimulation by Foliage Plant Display Images on Prefrontal Cortex Activity: A Comparison with Stimulation using Actual Foliage Plants. Journal of Neuroimaging, 25(1), 127-130. https://doi.org/10.1111/jon.12078 Janssen, I., Hanssen, M., Bak, M., Bijl, R. V., de Graaf, R., Vollebergh, W., ... van Os, J. (2003). Discrimination and delusional ideation. The British Journal of Psychiatry: The Journal of Mental Science, 182, 71-76.

Kapur, S. (2003). Psychosis as a State of Aberrant Salience: A Framework Linking Biology, Phenomenology, and Pharmacology in Schizophrenia. American Journal of Psychiatry, 160(1), 13. 
https://doi.org/10.1176/appi.ajp.160.1.13

Kelly, B. D., O'Callaghan, E., Waddington, J. L., Feeney, L., Browne, S., Scully, P. J., ... Larkin, C. (2010). Schizophrenia and the city: A review of literature and prospective study of psychosis and urbanicity in Ireland. Schizophrenia Research, 116(1), 75-89.

https://doi.org/10.1016/j.schres.2009.10.015

Kirkbride, J. B., Errazuriz, A., Croudace, T. J., Morgan, C., Jackson, D., Boydell, J., ... Jones, P. B. (2012). Incidence of schizophrenia and other psychoses in England, 1950-2009: a systematic review and meta-analyses. PloS One, 7(3), e31660. https://doi.org/10.1371/journal.pone.0031660

Kirkbride, J. B., Fearon, P., Morgan, C., Dazzan, P., Morgan, K., Tarrant, J., ... Jones, P. B. (2006). Heterogeneity in Incidence Rates of Schizophrenia and Other Psychotic Syndromes: Findings From the 3Center ÆESOP Study. Archives of General Psychiatry, 63(3), 250-258. https://doi.org/10.1001/archpsyc.63.3.250

Kirkbride, J. B., Hameed, Y., Ankireddypalli, G., Ioannidis, K., Crane, C. M., Nasir, M., ... Jones, P. B. (2017). The Epidemiology of First-Episode Psychosis in Early Intervention in Psychosis Services: Findings From the Social Epidemiology of Psychoses in East Anglia [SEPEA] Study. The American Journal of Psychiatry, 174(2), 143-153. https://doi.org/10.1176/appi.ajp.2016.16010103 
Kirkbride, J. B., Jones, P. B., Ullrich, S., \& Coid, J. W. (2014). Social deprivation, inequality, and the neighborhood-level incidence of psychotic syndromes in East London. Schizophrenia Bulletin, 40(1), 169-180. https://doi.org/10.1093/schbul/sbs151

Kirkbride, J. B., Morgan, C., Fearon, P., Dazzan, P., Murray, R. M., \& Jones, P. B. (2007). Neighbourhood-level effects on psychoses: re-examining the role of context. Psychological Medicine, 37(10), 1413-1425. https://doi.org/10.1017/S0033291707000499

Krabbendam, L., \& van Os, J. (2005). Schizophrenia and urbanicity: a major environmental influence--conditional on genetic risk. Schizophrenia Bulletin, 31(4), 795-799. https://doi.org/10.1093/schbul/sbi060

Kuepper, R., van Os, J., Lieb, R., Wittchen, H.-U., \& Henquet, C. (2011). Do cannabis and urbanicity co-participate in causing psychosis? Evidence from a 10-year follow-up cohort study. Psychological Medicine, 41(10), 2121-2129. https://doi.org/10.1017/S0033291711000511

Kumakura, Y., Cumming, P., Vernaleken, I., Buchholz, H.-G., Siessmeier, T., Heinz, A., ... Gründer, G. (2007). Elevated [18F]Fluorodopamine Turnover in Brain of Patients with Schizophrenia: An [18F]Fluorodopa/Positron Emission Tomography Study. Journal of Neuroscience, 27(30), 8080-8087. https://doi.org/10.1523/JNEUROSCI.0805-07.2007

Landon J, Shepherd D, McGarryy M, Theadom A, \& Miller R. (2016). When 
it's quiet, it's nice : noise sensitivity in schizophrenia. American Journal of Psychiatric Rehabilitation, 19(2), 122-135.

Laursen, T. M., Munk-Olsen, T., Nordentoft, M., \& Bo Mortensen, P. (2007). A comparison of selected risk factors for unipolar depressive disorder, bipolar affective disorder, schizoaffective disorder, and schizophrenia from a danish population-based cohort. The Journal of Clinical Psychiatry, 68(11), 1673-1681.

Lederbogen, F., Kirsch, P., Haddad, L., Streit, F., Tost, H., Schuch, P., ... Meyer-Lindenberg, A. (2011). City living and urban upbringing affect neural social stress processing in humans. Nature, 474(7352), 498501. https://doi.org/10.1038/nature10190

Light, G. A., \& Braff, D. L. (2003). Sensory gating deficits in schizophrenia: can we parse the effects of medication, nicotine use, and changes in clinical status? Clinical Neuroscience Research, 3(1), 47-54. https://doi.org/10.1016/S1566-2772(03)00018-5

Lysaker, P. H., \& Lysaker, J. T. (2010). Schizophrenia and Alterations in Selfexperience: A Comparison of 6 Perspectives. Schizophrenia Bulletin, 36(2), 331-340. https://doi.org/10.1093/schbul/sbn077

Marcelis, M., Navarro-Mateu, F., Murray, R., Selten, J. P., \& Van Os, J. (1998). Urbanization and psychosis: a study of 1942-1978 birth cohorts in The Netherlands. Psychological Medicine, 28(4), 871-879.

Marcelis, M., Takei, N., \& van Os, J. (1999). Urbanization and risk for 
schizophrenia: does the effect operate before or around the time of illness onset? Psychological Medicine, 29(5), 1197-1203.

March, D., Hatch, S. L., Morgan, C., Kirkbride, J. B., Bresnahan, M., Fearon, P., \& Susser, E. (2008). Psychosis and place. Epidemiologic Reviews, 30, 84-100. https://doi.org/10.1093/epirev/mxn006

Maric, N. P., \& Svrakic, D. M. (2012). Why schizophrenia genetics needs epigenetics: a review. Psychiatria Danubina, 24(1), 2-18.

Mcghie, A., \& Chapman, J. (1961). Disorders of attention and perception in early schizophrenia. The British Journal of Medical Psychology, 34, 103-116.

McGrath, J. (1999). Hypothesis: is low prenatal vitamin D a risk-modifying factor for schizophrenia? Schizophrenia Research, 40(3), 173-177.

McGrath, J. J., Burne, T. H., Féron, F., Mackay-Sim, A., \& Eyles, D. W. (2010). Developmental Vitamin D Deficiency and Risk of Schizophrenia: A 10-Year Update. Schizophrenia Bulletin, 36(6), 10731078. https://doi.org/10.1093/schbul/sbq101

McGrath, J., Saha, S., Welham, J., Saadi, O. El, MacCauley, C., \& Chant, D. (2004). A systematic review of the incidence of schizophrenia: the distribution of rates and the influence of sex, urbanicity, migrant status and methodology. BMC Medicine, 2, 13. https://doi.org/10.1186/1741$7015-2-13$

Meyer-Lindenberg, A., \& Tost, H. (2012). Neural mechanisms of social risk for 
psychiatric disorders. Nature Neuroscience, 15(5), 663-668. https://doi.org/10.1038/nn.3083

Mill, J., Tang, T., Kaminsky, Z., Khare, T., Yazdanpanah, S., Bouchard, L., ... Petronis, A. (2008). Epigenomic profiling reveals DNA-methylation changes associated with major psychosis. American Journal of Human Genetics, 82(3), 696-711. https://doi.org/10.1016/j.ajhg.2008.01.008

Mizrahi, R. (2016). Social Stress and Psychosis Risk: Common Neurochemical Substrates? Neuropsychopharmacology: Official Publication of the American College of Neuropsychopharmacology, 41(3), 666-674. https://doi.org/10.1038/npp.2015.274

Mizrahi, R., Addington, J., Rusjan, P. M., Suridjan, I., Ng, A., Boileau, I., ... Wilson, A. A. (2012). Increased stress-induced dopamine release in psychosis. Biological Psychiatry, 71(6), 561-567. https://doi.org/10.1016/j.biopsych.2011.10.009

Moore, T. H. M., Zammit, S., Lingford-Hughes, A., Barnes, T. R. E., Jones, P. B., Burke, M., \& Lewis, G. (2007). Cannabis use and risk of psychotic or affective mental health outcomes: a systematic review. Lancet (London, England), 370(9584), 319-328.

https://doi.org/10.1016/S0140-6736(07)61162-3

Morgan, C., Charalambides, M., Hutchinson, G., \& Murray, R. M. (2010). Migration, Ethnicity, and Psychosis: Toward a Sociodevelopmental Model. Schizophrenia Bulletin, 36(4), 655-664. 
https://doi.org/10.1093/schbul/sbq051

Morgan, C., Kirkbride, J., Hutchinson, G., Craig, T., Morgan, K., Dazzan, P., ... Fearon, P. (2008). Cumulative social disadvantage, ethnicity and first-episode psychosis: a case-control study. Psychological Medicine, 38(12), 1701-1715. https://doi.org/10.1017/S0033291708004534

Morgan, D., Grant, kathleen A., Gage, H. D., Mach, R. H., Kaplan, J. R., Prioleau, O., ... Nader, M. A. (2002). Social dominance in monkeys: Dopamine D2 receptors and cocaine self-administration. Nature Neuroscience, 5(2), 169-174. https://doi.org/10.1038/nn798

Mortensen, P. B., Pedersen, C. B., Westergaard, T., Wohlfahrt, J., Ewald, H., Mors, O., ... Melbye, M. (1999). Effects of family history and place and season of birth on the risk of schizophrenia. New England Journal of Medicine, 340(8), 603-608.

Murray, R. M., Lappin, J., \& Di Forti, M. (2008). Schizophrenia: From developmental deviance to dopamine dysregulation. European Neuropsychopharmacology, 18, S129-S134. https://doi.org/10.1016/j.euroneuro.2008.04.002

Nader, M. A., Morgan, D., Gage, H. D., Nader, S. H., Calhoun, T. L., Buchheimer, N., ... Mach, R. H. (2006). PET imaging of dopamine D2 receptors during chronic cocaine self-administration in monkeys. Nature Neuroscience, 9(8), 1050-1056.

Nelson, B., Parnas, J., \& Sass, L. A. (2014). Disturbance of Minimal Self 
(Ipseity) in Schizophrenia: Clarification and Current Status.

Schizophrenia Bulletin, 40(3), 479-482.

https://doi.org/10.1093/schbul/sbu034

Nelson, B., Whitford, T. J., Lavoie, S., \& Sass, L. A. (2014). What are the neurocognitive correlates of basic self-disturbance in schizophrenia?: Integrating phenomenology and neurocognition. Part 1 (Source monitoring deficits). Schizophrenia Research, 152(1), 12-19. https://doi.org/10.1016/j.schres.2013.06.022

Newbury, J., Arseneault, L., Caspi, A., Moffitt, T. E., Odgers, C. L., \& Fisher, H. L. (2016). Why Are Children in Urban Neighborhoods at Increased Risk for Psychotic Symptoms? Findings From a UK Longitudinal Cohort Study. Schizophrenia Bulletin, 42(6), 1372-1383. https://doi.org/10.1093/schbul/sbw052

Ødegård, $\varnothing$. (1932). Emigration and insanity; a study of mental disease among the Norwegian born population of Minnesota. Copenhagen: Levin \& Munksgaard.

O’Donoghue, B., Lyne, J. P., Renwick, L., Lane, A., Madigan, K., Staines, A., ... Clarke, M. (2016). Neighbourhood characteristics and the incidence of first-episode psychosis and duration of untreated psychosis. Psychological Medicine, 46(7), 1367-1378. https://doi.org/10.1017/S003329171500286X

Parr, H. (2007). Mental health, nature work, and social inclusion (journalArticle 
No. ISSN02637758). Retrieved from

http://www.IsIn.net.au/jspui/handle/1/11172

Pedersen, C. B. (2015). Persons with schizophrenia migrate towards urban areas due to the development of their disorder or its prodromata. Schizophrenia Research, 168(1), 204-208. https://doi.org/10.1016/j.schres.2015.08.028

Pedersen, C. B., \& Mortensen, P. B. (2001). Evidence of a Dose-Response Relationship Between Urbanicity During Upbringing and Schizophrenia Risk. Archives of General Psychiatry, 58(11), 1039-1046. https://doi.org/10.1001/archpsyc.58.11.1039

Pedersen, C. Вø., \& Mortensen, P. B. (2001). Family history, place and season of birth as risk factors for schizophrenia in Denmark: a replication and reanalysis. The British Journal of Psychiatry, 179(1), $46-52$.

Peen, J., Schoevers, R. A., Beekman, A. T., \& Dekker, J. (2010). The current status of urban-rural differences in psychiatric disorders. Acta Psychiatrica Scandinavica, 121(2), 84-93. https://doi.org/10.1111/j.1600-0447.2009.01438.x

Penkalla, A. M., \& Kohler, S. (2014). Urbanicity and Mental Health in Europe: A Systematic Review. European Journal of Mental Health, 9(02), 163177.

Pink, S. (2007). Walking with video. Visual Studies, 22(3), 240-252. 
https://doi.org/10.1080/14725860701657142

Postmes, L., Sno, H. N., Goedhart, S., van der Stel, J., Heering, H. D., \& de Haan, L. (2014). Schizophrenia as a self-disorder due to perceptual incoherence. Schizophrenia Research, 152(1), 41-50. https://doi.org/10.1016/j.schres.2013.07.027

Pruessner, J. C., Champagne, F., Meaney, M. J., \& Dagher, A. (2004). Dopamine Release in Response to a Psychological Stress in Humans and Its Relationship to Early Life Maternal Care: A Positron Emission Tomography Study Using [11C]Raclopride. Journal of Neuroscience, 24(11), 2825-2831. https://doi.org/10.1523/JNEUROSCI.3422-03.2004

Schreier, A., Wolke, D., Thomas, K., Horwood, J., Hollis, C., Gunnell, D., ... Harrison, G. (2009). Prospective study of peer victimization in childhood and psychotic symptoms in a nonclinical population at age 12 years. Archives of General Psychiatry, 66(5), 527-536. https://doi.org/10.1001/archgenpsychiatry.2009.23

Selten, J.-P., \& Cantor-Graae, E. (2005). Social defeat: risk factor for schizophrenia? The British Journal of Psychiatry, 187(2), 101-102. https://doi.org/10.1192/bjp.187.2.101

Selten, J.-P., van der Ven, E., Rutten, B. P. F., \& Cantor-Graae, E. (2013). The Social Defeat Hypothesis of Schizophrenia: An Update. Schizophrenia Bulletin, 39(6), 1180-1186. https://doi.org/10.1093/schbul/sbt134 
Söderström, O., Empson, L. A., Codeluppi, Z., Söderström, D., Baumann, P. S., \& Conus, P. (2016). Unpacking 'the City': An experience-based approach to the role of urban living in psychosis. Health \& Place, 42 , 104-110. https://doi.org/10.1016/j.healthplace.2016.09.002

Söderström, O., Söderström, D., Codeluppi, Z., Empson, L. A., \& Conus, P. (2017). Emplacing recovery: how persons diagnosed with psychosis handle stress in cities. Psychosis, 1-8. https://doi.org/10.1080/17522439.2017.1344296

Song, C., Ikei, H., Igarashi, M., Miwa, M., Takagaki, M., \& Miyazaki, Y. (2014). Physiological and psychological responses of young males during spring-time walks in urban parks. Journal of Physiological Anthropology, 33(1), 8. https://doi.org/10.1186/1880-6805-33-8

Sørensen, H. J., Nielsen, P. R., Pedersen, C. B., Benros, M. E., Nordentoft, M., \& Mortensen, P. B. (2014). Population impact of familial and environmental risk factors for schizophrenia: a nationwide study. Schizophrenia Research, 153(1-3), 214-219. https://doi.org/10.1016/j.schres.2014.01.008

Spauwen, J., Krabbendam, L., Lieb, R., Wittchen, H.-U., \& van Os, J. (2004). Does urbanicity shift the population expression of psychosis? Journal of Psychiatric Research, 38(6), 613-618. https://doi.org/10.1016/j.jpsychires.2004.04.003

Steen, N. E., Methlie, P., Lorentzen, S., Hope, S., Barrett, E. A., Larsson, S., 
... Andreassen, O. A. (2011). Increased systemic cortisol metabolism in patients with schizophrenia and bipolar disorder: a mechanism for increased stress vulnerability? The Journal of Clinical Psychiatry, 72(11), 1515-1521. https://doi.org/10.4088/JCP.10m06068yel

Stephan, K. E., Friston, K. J., \& Frith, C. D. (2009). Dysconnection in Schizophrenia: From Abnormal Synaptic Plasticity to Failures of Selfmonitoring. Schizophrenia Bulletin, 35(3), 509-527. https://doi.org/10.1093/schbul/sbn176

Sundquist, K., Frank, G., \& Sundquist, J. (2004). Urbanisation and incidence of psychosis and depression: Follow-up study of 4.4 million women and men in Sweden. The British Journal of Psychiatry, 184(4), 293-298. https://doi.org/10.1192/bjp.184.4.293

Susser, E. S., Schaefer, C. A., Brown, A. S., Begg, M. D., \& Wyatt, R. J. (2000). The design of the prenatal determinants of schizophrenia study. Schizophrenia Bulletin, 26(2), 257-273.

Szöke, A., Charpeaud, T., Galliot, A.-M., Vilain, J., Richard, J.-R., Leboyer, M., ... Schürhoff, F. (2014). Rural-urban variation in incidence of psychosis in France: a prospective epidemiologic study in two contrasted catchment areas. BMC Psychiatry, 14, 78. https://doi.org/10.1186/1471-244X-14-78

Torrey, E. F., Bartko, J. J., Lun, Z.-R., \& Yolken, R. H. (2007). Antibodies to Toxoplasma gondii in Patients With Schizophrenia: A Meta-Analysis. 
Schizophrenia Bulletin, 33(3), 729-736.

https://doi.org/10.1093/schbul/sbl050

Tost, H., Champagne, F. A., \& Meyer-Lindenberg, A. (2015). Environmental influence in the brain, human welfare and mental health. Nature Neuroscience, 18(10), 1421-1431. https://doi.org/10.1038/nn.4108

Tost, H., \& Meyer-Lindenberg, A. (2012). Puzzling over schizophrenia: schizophrenia, social environment and the brain. Nature Medicine, 18(2), 211-213. https://doi.org/10.1038/nm.2671

Tregellas, J. R., Davalos, D. B., Rojas, D. C., Waldo, M. C., Gibson, L., Wylie, K., ... Freedman, R. (2007). Increased hemodynamic response in the hippocampus, thalamus and prefrontal cortex during abnormal sensory gating in schizophrenia. Schizophrenia Research, 92(1), 262-272. https://doi.org/10.1016/j.schres.2006.12.033

Tregellas, J. R., Ellis, J., Shatti, S., Du, Y. P., \& Rojas, D. C. (2009). Increased hippocampal, thalamic, and prefrontal hemodynamic response to an urban noise stimulus in schizophrenia. The American Journal of Psychiatry, 166(3), 354.

https://doi.org/10.1176/appi.ajp.2008.08030411

United Nations Population Fund. (n.d.). State of World Population 2011 | UNFPA - United Nations Population Fund. Retrieved 6 August 2017, from http://www.unfpa.org/publications/state-world-population-2011 Valmaggia, L. R., Day, F., \& Rus-Calafell, M. (2016). Using virtual reality to 
investigate psychological processes and mechanisms associated with the onset and maintenance of psychosis: a systematic review. Social Psychiatry and Psychiatric Epidemiology, 51(7), 921-936.

https://doi.org/10.1007/s00127-016-1245-0

van der Ven, E., Dalman, C., Wicks, S., Allebeck, P., Magnusson, C., van Os, J., \& Selten, J. P. (2015). Testing Ødegaard's selective migration hypothesis: a longitudinal cohort study of risk factors for non-affective psychotic disorders among prospective emigrants. Psychological Medicine, 45(4), 727-734.

https://doi.org/10.1017/S0033291714001780

Van Os, J. (2004). Does the urban environment cause psychosis? The British Journal of Psychiatry, 184(4), 287-288.

https://doi.org/10.1192/bjp.184.4.287

van Os, J., Rutten, B. P., \& Poulton, R. (2008). Gene-Environment Interactions in Schizophrenia: Review of Epidemiological Findings and Future Directions. Schizophrenia Bulletin, 34(6), 1066-1082. https://doi.org/10.1093/schbul/sbn117

van Os, J., Verhagen, S., Marsman, A., Peeters, F., Bak, M., Marcelis, M., ... Delespaul, P. (2017). The experience sampling method as an mHealth tool to support self-monitoring, self-insight, and personalized health care in clinical practice. Depression and Anxiety, 34(6), 481-493. https://doi.org/10.1002/da.22647 
van Winkel, R., Stefanis, N. C., \& Myin-Germeys, I. (2008). Psychosocial Stress and Psychosis. A Review of the Neurobiological Mechanisms and the Evidence for Gene-Stress Interaction. Schizophrenia Bulletin, 34(6), 1095-1105. https://doi.org/10.1093/schbul/sbn101

Vassos, E., Pedersen, C. B., Murray, R. M., Collier, D. A., \& Lewis, C. M. (2012). Meta-Analysis of the Association of Urbanicity With Schizophrenia. Schizophrenia Bulletin, 38(6), 1118-1123. https://doi.org/10.1093/schbul/sbs096

Veling, W., Hoek, H. W., Wiersma, D., \& Mackenbach, J. P. (2010). Ethnic Identity and the Risk of Schizophrenia in Ethnic Minorities: A CaseControl Study. Schizophrenia Bulletin, 36(6), 1149-1156. https://doi.org/10.1093/schbul/sbp032

Veling, W., Pot-Kolder, R., Counotte, J., van Os, J., \& van der Gaag, M. (2016). Environmental Social Stress, Paranoia and Psychosis Liability: A Virtual Reality Study. Schizophrenia Bulletin, 42(6), 1363-1371. https://doi.org/10.1093/schbul/sbw031

Veling, W., Susser, E., Selten, J.-P., \& Hoek, H. W. (2015). Social disorganization of neighborhoods and incidence of psychotic disorders: a 7-year first-contact incidence study. Psychological Medicine, 45(9), 1789-1798. https://doi.org/10.1017/S0033291714002682

Veling, W., Susser, E., van Os, J., Mackenbach, J. P., Selten, J., \& Hoek, H. W. (2008). Ethnic Density of Neighborhoods and Incidence of 
Psychotic Disorders Among Immigrants. The American Journal of Psychiatry, 165(1), 66-73.

Veling, W., van der Pot-Kolder, R., Counotte, J., \& van der Gaag, M. (2015).

Virtual reality experiments linking social environment, stress

sensitization and psychosis. Schizophrenia Research, (Suppl).

Retrieved from https://research.vu.nl/en/publications/virtual-realityexperiments-linking-social-environment-stress-sen

Vilain, J., Galliot, A.-M., Durand-Roger, J., Leboyer, M., Llorca, P.-M., Schürhoff, F., \& Szöke, A. (2013). Les facteurs de risque environnementaux de la schizophrénie. L'Encéphale, 39(1), 19-28. https://doi.org/10.1016/j.encep.2011.12.007

Vlahov, D., \& Galea, S. (2002). Urbanization, urbanicity, and health. Journal of Urban Health: Bulletin of the New York Academy of Medicine, 79(4 Suppl 1), S1-S12.

Weidenauer, A., Bauer, M., Sauerzopf, U., Bartova, L., Praschak-Rieder, N., Sitte, H. H., ... Willeit, M. (2017). Making Sense of: Sensitization in Schizophrenia. International Journal of Neuropsychopharmacology, 20(1), 1-10. https://doi.org/10.1093/ijnp/pyw081

Wright, B., Peters, E., Ettinger, U., Kuipers, E., \& Kumari, V. (2014). Understanding noise stress-induced cognitive impairment in healthy adults and its implications for schizophrenia. Noise and Health, 16(70), 166. https://doi.org/10.4103/1463-1741.134917 
Yolken, R. H., Dickerson, F. B., \& Torrey, E. F. (2009). Toxoplasma and schizophrenia. Parasite Immunology, 31(11), 706-715. https://doi.org/10.1111/j.1365-3024.2009.01131.x

Zammit, S., Lewis, G., Rasbash, J., Dalman, C., Gustafsson, J.-E., \& Allebeck, P. (2010). Individuals, Schools, and Neighborhood: A Multilevel Longitudinal Study of Variation in Incidence of Psychotic Disorders. Archives of General Psychiatry, 67(9), 914-922. https://doi.org/10.1001/archgenpsychiatry.2010.101 


\begin{tabular}{|c|c|c|c|}
\hline & $\begin{array}{l}\text { Viral infections, specifically } \\
\text { influenza, genitourinary } \\
\text { infections and toxoplasmosis }\end{array}$ & & Fœtal exposure to maternal proinflammatory cytokines \\
\hline & $\begin{array}{l}\text { Maternal nutritional } \\
\text { deficiency (protein, folate, } \\
\text { choline, vitamin B12) }\end{array}$ & & $\begin{array}{l}\text { Deleterious effects on brain development du to S- } \\
\text { adenosylmethionine deficiency and subsequent "stress } \\
\text { sensitization" }\end{array}$ \\
\hline & Winter birth & & $\begin{array}{l}\text { Deleterious effects on brain development mediated by Vitamin } \mathrm{D} \\
\text { deficiency }\end{array}$ \\
\hline & & $\begin{array}{l}\text { Indirect social effect through } \\
\text { maternal stress or depression }\end{array}$ & Predisposition to subsequent hyperdopaminergia \\
\hline \multicolumn{4}{|l|}{ Postnatal "second hit" } \\
\hline & & $\begin{array}{l}\text { Adverse life events } \\
\text { (childhood trauma du to } \\
\text { abuse, neglect, bullying, } \\
\text { harsh familial environment) }\end{array}$ & \multirow{4}{*}{$\begin{array}{l}\text { Social defeat as a psychological mechanisms mediated by } \\
\text { increased mesolimbic DA transmission and sensitization to DA }\end{array}$} \\
\hline & & $\begin{array}{l}\text { Neighbourhood organisation, } \\
\text { deprivation and ethnic } \\
\text { composition }\end{array}$ & \\
\hline & & Migration & \\
\hline & & Discrimination or stigma & \\
\hline
\end{tabular}

This article is protected by copyright. All rights reserved. 


\section{University Library}

\section{- M M N E R VA A gateway to Melbourne's research publications}

Minerva Access is the Institutional Repository of The University of Melbourne

Author/s:

Empson, LA;Baumann, PS;Soderstrom, O;Codeluppi, Z;Soderstrom, D;Conus, P

Title:

Urbanicity: The need for new avenues to explore the link between urban living and psychosis

Date:

2019-08-06

Citation:

Empson, L. A., Baumann, P. S., Soderstrom, O., Codeluppi, Z., Soderstrom, D. \& Conus, P. (2019). Urbanicity: The need for new avenues to explore the link between urban living and psychosis. EARLY INTERVENTION IN PSYCHIATRY, 14 (4), pp.398-409. https:// doi.org/10.1111/eip.12861.

Persistent Link:

http://hdl.handle.net/11343/286252 